\title{
Children's measured exposure to food and beverage advertising on television in Toronto (Canada), May 2011-May 2019
}

\author{
Elise Pauzé ${ }^{1,2} \cdot$ Monique Potvin Kent ${ }^{1}$
}

Received: 12 November 2020 / Accepted: 8 April 2021 / Published online: 15 June 2021

(C) The Author(s) 2021

\begin{abstract}
Objective Exposure to unhealthy food advertising is a known determinant of children's poor dietary behaviours. The purpose of this study was to quantify and characterize Canadian children's exposure to food advertising on broadcast television and examine trends over time. Methods Objectively measured advertising exposure data for 19 food categories airing on 30 stations broadcast in Toronto were licenced for May 2011 and May 2019. Using ad ratings data, the average number of food advertisements viewed by children aged 2-11 years, overall, by food category and by type of television station (child-appealing, adolescent-appealing and generalist stations), was estimated per time period.

Results In May 2019, children viewed an average of 136 food advertisements on television, 20\% fewer than in May 2011. More than half of advertisements viewed in May 2019 promoted unhealthy food categories such as fast food (43\% of exposure), candy $(6 \%)$, chocolate $(6 \%)$ and regular soft drinks $(5 \%)$ and only $17 \%$ of their total exposure occurred on child-appealing stations. Between May 2011 and May 2019, children's exposure increased the most, in absolute terms, for savory snack foods $(+7.2$ ad exposures/child), fast food (+5.4) and regular soft drinks $(+5.3)$ with most of these increases occurring on generalist stations.

Conclusion Canadian children are still exposed to advertisements promoting unhealthy food categories on television despite voluntary restrictions adopted by some food companies. Statutory restrictions should be adopted and designed such that children are effectively protected from unhealthy food advertising on both stations intended for general audiences and those appealing to younger audiences.
\end{abstract}

\section{Résumé}

Objectif Cette étude quantifiait et décrivait l'exposition des enfants canadiens à la publicité alimentaire télévisuelle et examinait l'évolution des tendances.

Méthode Des données sur l'exposition publicitaire pour 19 catégories alimentaires diffusées sur 30 postes de télévision à Toronto ont été obtenues sous licence pour les mois de mai 2011 et mai 2019. Le nombre moyen de publicités visionnées par enfant âgé de 2 à 11 ans, au total, par catégorie d'aliments et par type de poste (attrayants auprès d'enfants, d'adolescents ou d'un large public), a été estimé pour chaque période.

Résultats En mai 2019, les enfants ont visionné, en moyenne, 136 publicités alimentaires télévisuelles, soit $20 \%$ de moins qu'en mai 2011. Plus de la moitié de leur exposition publicitaire en mai 2019 faisait la promotion de catégories d'aliments malsains tels que la restauration rapide (43\% de l'exposition), les bonbons (6\%), le chocolat (6\%) et les boissons gazeuses (5\%), et seulement $17 \%$ de leur exposition totale est survenue sur les postes attrayants auprès d'enfants. De mai 2011 à mai 2019, l'exposition des enfants a augmenté le plus, en nombre absolu, pour les collations salées $(+7,2$ publicités/enfant), la restauration rapide $(+5,4)$ et les boissons gazeuses $(+5,3)$, la majorité de ces augmentations survenant sur les postes généralistes.

Conclusion Les enfants sont exposés à la publicité alimentaire télévisuelle malsaine malgré les restrictions volontaires adoptées par certaines compagnies alimentaires. Des lois protégeant adéquatement les enfants contre les publicités malsaines diffusées sur les postes généralistes et ceux attrayant aux jeunes devraient être envisagées.

Monique Potvin Kent

monique.potvinkent@uottawa.ca
2 Interdisciplinary School of Health Sciences, Faculty of Health Sciences, University of Ottawa, Ottawa, ON, Canada

1 School of Epidemiology and Public Health, Faculty of Medicine,

University of Ottawa, 600 Peter Morand Crescent,

Ottawa, Ontario K1G 5Z3, Canada 
Keywords Public policy $\cdot$ Childhood obesity $\cdot$ Prevention $\cdot$ Food advertising

Mots-clés Politique publique $\cdot$ obésité infantile $\cdot$ prévention $\cdot$ publicités alimentaires

\section{Introduction}

In Canada, high body mass index and dietary risk factors are responsible for the second and fifth largest burden of disease in the country, respectively (Institute for Health Metrics and Evaluation, 2019). The nutritional health of Canadian children is of particular concern given that $31 \%$ of them have excess weight or obesity and most have diets inconsistent with national dietary guidelines, with ultra-processed foods which are typically high in sodium, fat and/or sugar accounting for more than half $(52-57 \%)$ of their caloric intake on average (Jessri et al., 2016; Moubarac, 2017; Rao et al., 2016). As dietary behaviours are often established during childhood, this constitutes a critical period during which healthy dietary patterns should be promoted (Birch et al., 2007).

Food and beverage marketing, which overwhelmingly promotes energy-dense and nutrient-poor foods, has been established as an environmental determinant of children's poor dietary behaviours (McGinnis et al., 2006; Norman et al., 2016; Sadeghirad et al., 2016). Several systematic reviews have concluded that food advertising influences the food purchases requested by children, their food preferences and their food intake during or immediately after exposure (McGinnis et al., 2006; Norman et al., 2016; Sadeghirad et al., 2016). Notably, a recent experimental study found that children do not compensate for the increased caloric intake that occurs after their exposure to food advertising at subsequent eating occasions, thereby strengthening the evidence of a causal link between exposure to food advertising and childhood obesity (Norman et al., 2018). Children's heightened susceptibility to advertising stems in part from their inability to decipher commercial messages from other content before the age of 6 and to consistently understand advertising's persuasive intentions by age 12 (Carter et al., 2011; Wilcox et al., 2004). As such, it is being increasingly argued that protecting children from unhealthy food advertising is necessary to uphold children's right to health (Garde et al., 2018). There is in fact a global consensus that the marketing of foods high in sugar, fat and sodium to children should be restricted (World Health Organization, 2010).

Among Canadian children, television remains a significant source of exposure to advertising. In 2017/2018, children aged 2-11 years watched an average of $17.3 \mathrm{~h}$ of television per week according to measured media data, which exceeds current guidelines recommending recreational daily screen time be limited to $2 \mathrm{~h}$ or less among school-aged children (Canadian RadioTelevision and Telecommunications Commission (CRTC), 2017; Canadian Society for Exercise Physiology, 2016).
Currently, food advertising to children on television is mostly regulated by an industry-led voluntary initiative introduced in 2007 to which 16 companies, including McDonald's, Kellogg's and Hershey's among others, currently participate (Ad Standards, 2019). Research however has shown that this initiative has been largely ineffective at improving the healthfulness of foods and beverages promoted to children on television (Potvin Kent \& Wanless, 2014; Potvin Kent et al., 2011a; Kelly et al., 2019; Potvin Kent et al., 2018). For instance, a recent international study found that advertisements promoting unhealthy foods on three Canadian child speciality stations outnumbered those promoting healthier products by a factor of 12 and Canada had by far the highest rate of unhealthy food advertising $(9.7 \mathrm{ads} / \mathrm{h} / \mathrm{station})$ compared with 21 other countries (the second highest being Spain at $5.2 \mathrm{ads} / \mathrm{h} / \mathrm{station}$ ) (Kelly et al., 2019). While most Canadian studies have focused on the frequency and/or healthfulness of food advertising on children's speciality stations (Kelly et al., 2019), on child programming (Pinto et al., 2020) or on programs where children constitute a large proportion of viewers (Potvin Kent et al., 2018), comparatively fewer have examined children's actual exposure using objectively measured media data (Potvin Kent \& Wanless, 2014).

Recently, the federal government considered the Child Health Protection Act, a Bill that proposed restricting the advertising of foods and beverages high in sodium, saturated fat and sugar to children under 13 years in various media channels and settings (Senate of Canada, 2017; Health Canada, 2018). While this proposed Bill died on the order paper in June 2019, the current government has signaled its intention to introduce new restrictions to food marketing (Office of the Prime Minister, 2019). Considering these forthcoming restrictions, this study sought to provide critical baseline data needed to assess the impact of these restrictions and inform policy decisions regarding food advertising to children. Specifically, our objectives were to (1) determine the frequency of food and beverage advertising on broadcast television in a Canadian context, (2) estimate children's exposure to this advertising using objectively measured exposure data, (3) examine children's exposure by food category and type of station, and (4) describe changes in advertising frequency and exposure over time.

\section{Methods}

Television audience measurement data were licenced from Numeris while television advertising data for 19 food categories broadcast on 31 to 35 television stations in Toronto were 
licenced from Nielsen Media Research for the month of May in 2011, 2013 and 2016 and from Numerator (formerly owned by Nielsen) for May 2019. Toronto was chosen because it is the largest Canadian broadcast market. The month of May was selected because it excludes any major holidays which may influence typical advertising spending and exposure. Four weeks of 24-h television programming for each period were included in the study (May 1 to May 28, 2011; April 28 to May 25, 2013; May 1 to May 28, 2016; and April 28 to May 25, 2019). These four years were selected as these data were previously licenced for other research (Potvin Kent et al., 2018). The 19 licenced food categories were cakes, candy, cold cereal, cheese, chocolate, compartment snacks, cookies, energy drinks, ice cream, juices, fruit nectars and drinks, frozen pizza, portable snacks, fast food restaurants, sit-down restaurants, snack foods, diet soft drinks, regular soft drinks, sports drinks and yogurt (see Supplemental Table 1 for a detailed description). These food categories were established by Nielsen/Numerator and were chosen because they constitute the most frequently advertised food categories to children (Kelly et al., 2019; Potvin Kent et al., 2011b).

The licenced data provide viewership information for all food advertisements that aired during the examined period. Audience viewership data are collected from a stratified probability sample of households that is proportional to the population. To capture viewership, data are collected on the time and station at which the television sets of households are tuned. Portable devices worn by each household member also record who is near the television when it is turned on. Being in the proximity of the television is therefore used as a proxy for viewership. To estimate audience viewership at the market level, data are weighted based on several characteristics, including age, sex, household size and type of television reception, among others. Ad viewership is then expressed as 'rating points' which is the estimated percentage of the population or selected age group who viewed the advertisement. To estimate the number of advertisements seen, on average, per child, the rating points for advertisements viewed by children aged 2 to 11 years were summed, overall and by food category, and then divided by 100 . The sample of children on which exposure was estimated varied between May $2011(n=96)$, May 2013 $(n=187)$, May $2016(n=149)$ and May $2019(n=177)$. In May 2011, 2013 and 2016, rating points were reported by advertisement, whereas in May 2019, these were sometimes reported by advertised product. Data from May 2019 were therefore reviewed to remove duplicate advertisements and ensure data could be compared across time. In cases from May 2019 where multiple food categories were promoted within the same advertisement, the advertisement was classified into a single category in a manner consistent with data from previous years. For instance, ads promoting both cold cereal and portable snacks were classified under cold cereal exclusively while ads promoting both regular and diet soft drinks were classified under regular soft drinks.
In 2011, data from 34 stations were available; however, four were excluded from the study as Nielsen/Numerator stopped recording the advertisements on these stations before May 2019. The 30 stations included in the study were grouped into three station categories: child-appealing stations $(n=2)$, adolescent-appealing stations $(n=2)$ and generalist stations $(n=26)$. Teletoon and YTV were classified as child-appealing stations as most of their programs targeted children 12 years and younger. MTV and Much were deemed adolescentappealing stations because much of their programming centered on either sitcoms, reality television and celebrity entertainment targeting or appealing to youth (i.e., MTV; e.g., Degrassi, Teen Mom, Ridiculousness, TMZ) or popular music and youth-appealing comedy shows and sitcoms (i.e., Much; e.g., Playlist, Tosh.O, South Park). A complete list of included stations is provided in Supplemental Table 2.

\section{Analysis}

Nielsen's Spotwatch software was used to extract television advertising data from May of 2011, 2013 and 2016, while Numerator's Ad Quest software was used to extract data from May 2019. Datafiles were merged into one and analyses were conducted using SPSS version 27 (IBM 2020). The frequency of food advertising and children's exposure on all stations was determined (overall and by food category) for each period. Food advertising frequency and exposure were tabulated by station category and described using frequencies. Absolute differences and percent changes in frequency and exposure between May 2011 and May 2019 were also calculated. For May 2019, the share of children's exposure coming from child-appealing stations versus all other stations, overall and within food categories, was determined. Chi-square and post hoc $z$-tests with Bonferroni correction were performed to test differences in the distribution of ads by food category across examined periods, overall and by station category, when test assumptions were met. $p$ values below 0.05 were considered statistically significant.

\section{Results}

\section{Changes in food advertising across all stations}

Overall, 80,018, 77,668, 84,361 and 102,409 food advertisements were broadcast on television in May of 2011, 2013, 2016 and 2019, respectively (Table 1). The distribution of ads by food category differed significantly across time $\left(\chi^{2}=\right.$ 34,206.765; $d f=54 ; p<0.001$ ). In May 2011, the most advertised food categories were fast food (33.0\% of total ads), chocolate $(11.4 \%)$ and yogurt $(9.1 \%)$, while the most advertised food categories in May 2019 were fast food (44.2\%), 
chocolate $(8.3 \%)$ and cereal $(8.3 \%)$. Between these two periods, the total frequency of ads increased by $28 \%$; however, changes over time varied by food category. The largest relative increases were noted for cakes $(+3392 \%)$ and regular soft drinks $(+412 \%)$, while the largest relative decreases occurred for sports drinks $(-95 \%)$ and portable snacks $(-94 \%)$. In absolute terms, the greatest increases were noted for fast food $(+18,907$ ads), snack foods $(+4937)$ and regular soft drinks $(+4481)$, while the largest decreases were noted for yogurt $(-4675)$, cookies $(-2736)$ and portable snacks $(-2246)$. The absolute and relative frequency of ads promoting snack foods and regular soft drinks increased steadily across all examined time periods while decreasing steadily for cookies, portable snacks and yogurt. For most other food categories, no consistent temporal trend was noted.

\section{Changes in food advertising by station category}

On child-appealing stations, a total of $6173,6274,10,733$ and 9832 food advertisements were broadcast in May of 2011, 2013, 2016 and 2019, respectively (Table 2). In May 2011, the most advertised food categories were fast food $(33.0 \%$ of total ads), cereal $(13.8 \%)$ and cheese $(12.5 \%)$, while in May 2019, these were cold cereal (30.6\%), fast food $(21.8 \%)$ and candy (19.2\%). Between May 2011 and May 2019, the total number of food advertisements on child-appealing stations increased by $59 \%$. The greatest relative increases between these two periods were noted for ice cream $(+2385 \%)$ and candy $(+670 \%)$, while the largest relative decreases were noted for cookies $(-100 \%)$, pizza $(-100 \%)$ and regular soft drinks $(-100 \%)$. The largest absolute increases between these two periods occurred for cereal (+2156 ads) and candy (+1641), while the largest absolute decreases were noted for portable snacks $(-383)$ and cookies (-359). For most food categories, there was no consistent temporal trend in advertising frequency across all examined periods. Only the number of cookie advertisements decreased steadily over time. Diet soft drinks and sports drinks were not advertised at all on child-appealing stations across all examined periods.

Overall, a total of 4530, 6966, 5964 and 11,085 food advertisements were broadcast on adolescent-appealing stations in

Table 1 Number of food and beverage advertisements broadcast on 30 television stations in Toronto (Canada) in May of 2011, 2013, 2016 and 2019, overall and by food category

\begin{tabular}{|c|c|c|c|c|c|c|}
\hline Food/beverage category & May $2011, n(\%)$ & May $2013, n(\%)$ & May $2016, n(\%)$ & May $2019, n(\%)$ & $\begin{array}{l}\text { \% change, } \\
\text { May } 2011 \text { to } \\
\text { May } 2019\end{array}$ & $\begin{array}{l}\text { Absolute difference, } \\
\text { May } 2019 \text { vs } \\
\text { May } 2011\end{array}$ \\
\hline Cakes & $52(0.1)^{\mathrm{a}}$ & $3(<0.1)^{\mathrm{a}}$ & $423(0.5)^{\mathrm{a}}$ & $1816(1.8)^{\mathrm{a}}$ & $+3392 \%$ & +1764 \\
\hline Candy & $783(1.0)^{\mathrm{a}}$ & $4559(5.9)^{\mathrm{a}}$ & $3610(4.3)^{\mathrm{a}}$ & $3993(3.9)^{\mathrm{a}}$ & $+410 \%$ & +3210 \\
\hline Cereal & $7074(8.8)^{\mathrm{a}}$ & $2970(3.8)^{\mathrm{a}}$ & $2915(3.5)^{\mathrm{a}}$ & $8454(8.3)^{\mathrm{a}}$ & $+20 \%$ & +1380 \\
\hline Cheese & $5497(6.9)^{\mathrm{a}}$ & $3674(4.7)^{\mathrm{a}}$ & $4628(5.5)^{\mathrm{a}}$ & $3262(3.2)^{\mathrm{a}}$ & $-41 \%$ & -2235 \\
\hline Chocolate & $9140(11.4)^{\mathrm{a}, \mathrm{b}}$ & $10,922(14.1)^{\mathrm{a}, \mathrm{b}}$ & $6771(8.0)^{\mathrm{a}}$ & $8463(8.3)^{\mathrm{b}}$ & $-7 \%$ & -677 \\
\hline Compartment snacks & $0(0)^{\mathrm{a}}$ & $260(0.3)^{\mathrm{a}, \mathrm{b}, \mathrm{c}}$ & $0(0)^{\mathrm{b}}$ & $0(0)^{\mathrm{c}}$ & - & 0 \\
\hline Cookies & $3765(4.7)^{\mathrm{a}}$ & $2210(2.8)^{\mathrm{a}}$ & $1387(1.6)^{\mathrm{a}}$ & $1029(1.0)^{\mathrm{a}}$ & $-73 \%$ & -2736 \\
\hline Energy drinks & $765(1.0)$ & $804(1.0)$ & $857(1.0)$ & $957(0.9)$ & $+25 \%$ & +192 \\
\hline Ice cream & $1254(1.6)^{\mathrm{a}}$ & $2136(2.8)^{\mathrm{a}, \mathrm{b}}$ & $2612(3.1)^{\mathrm{a}, \mathrm{b}}$ & $1574(1.5)^{\mathrm{b}}$ & $+26 \%$ & +320 \\
\hline $\begin{array}{l}\text { Juices, drinks and } \\
\text { nectars }\end{array}$ & $3427(4.3)^{\mathrm{a}, \mathrm{b}}$ & $4321(5.6)^{\mathrm{a}}$ & $4831(5.7)^{\mathrm{b}}$ & $3214(3.1)^{\mathrm{a}, \mathrm{b}}$ & $-6 \%$ & -213 \\
\hline Pizza & $2148(2.7)^{\mathrm{a}}$ & $1207(1.6)^{\mathrm{a}}$ & $1498(1.8)^{\mathrm{a}}$ & $1143(1.1)^{\mathrm{a}}$ & $-47 \%$ & -1005 \\
\hline Portable snacks & $2397(3.0)^{\mathrm{a}}$ & $1892(2.4)^{\mathrm{a}}$ & $1739(2.1)^{\mathrm{a}}$ & $151(0.1)^{\mathrm{a}}$ & $-94 \%$ & -2246 \\
\hline Restaurant - fast food & $26,370(33.0)^{\mathrm{a}}$ & $25,038(32.2)^{\mathrm{a}}$ & $34,041(40.4)^{\mathrm{a}}$ & $45,277(44.2)^{\mathrm{a}}$ & $+72 \%$ & $+18,907$ \\
\hline Restaurant - sit-down & $5686(7.1)^{\mathrm{a}}$ & $4441(5.7)^{\mathrm{a}, \mathrm{b}}$ & $5480(6.5)^{\mathrm{a}, \mathrm{b}}$ & $7405(7.2)^{\mathrm{b}}$ & $+30 \%$ & +1719 \\
\hline Snack foods & $2142(2.7)^{\mathrm{a}, \mathrm{b}}$ & $4850(6.2)^{\mathrm{a}, \mathrm{b}}$ & $5600(6.6)^{\mathrm{a}}$ & $7079(6.9)^{\mathrm{b}}$ & $+230 \%$ & +4937 \\
\hline Soft drinks - diet & $804(1.0)^{\mathrm{a}, \mathrm{b}}$ & $0(0)^{a, b}$ & $318(0.4)^{\mathrm{a}}$ & $413(0.4)^{\mathrm{b}}$ & $-49 \%$ & -391 \\
\hline Soft drinks - regular & $1088(1.4)^{\mathrm{a}, \mathrm{b}}$ & $3663(4.7)^{\mathrm{a}}$ & $3999(4.7)^{\mathrm{b}}$ & $5569(5.4)^{\mathrm{a}, \mathrm{b}}$ & $+412 \%$ & +4481 \\
\hline Sports drinks & $360(0.4)^{\mathrm{a}}$ & $83(0.1)^{\mathrm{a}}$ & $1006(1.2)^{\mathrm{a}}$ & $19(<0.1)^{\mathrm{a}}$ & $-95 \%$ & -341 \\
\hline Yogurt & $7266(9.1)^{\mathrm{a}}$ & $4635(6.0)^{\mathrm{a}}$ & $2646(3.1)^{\mathrm{a}}$ & $2591(2.5)^{\mathrm{a}}$ & $-64 \%$ & -4675 \\
\hline Total & $80,018(100)$ & $77,668(100)$ & $84,361(100)$ & $102,409(100)$ & $+28 \%$ & $+22,391$ \\
\hline
\end{tabular}

The distribution of food ads by food category differs significantly across examined time periods $\left(\chi^{2}=34206.765 ; d f=54 ; p<0.001\right)$. Within rows, matching letters in superscript denote proportions that differ significantly $(p<0.05)$ according to post hoc $z$-tests with Bonferroni correction. Data source: Nielsen Media Research (2011, 2013, 2016) and Numerator (2019) 


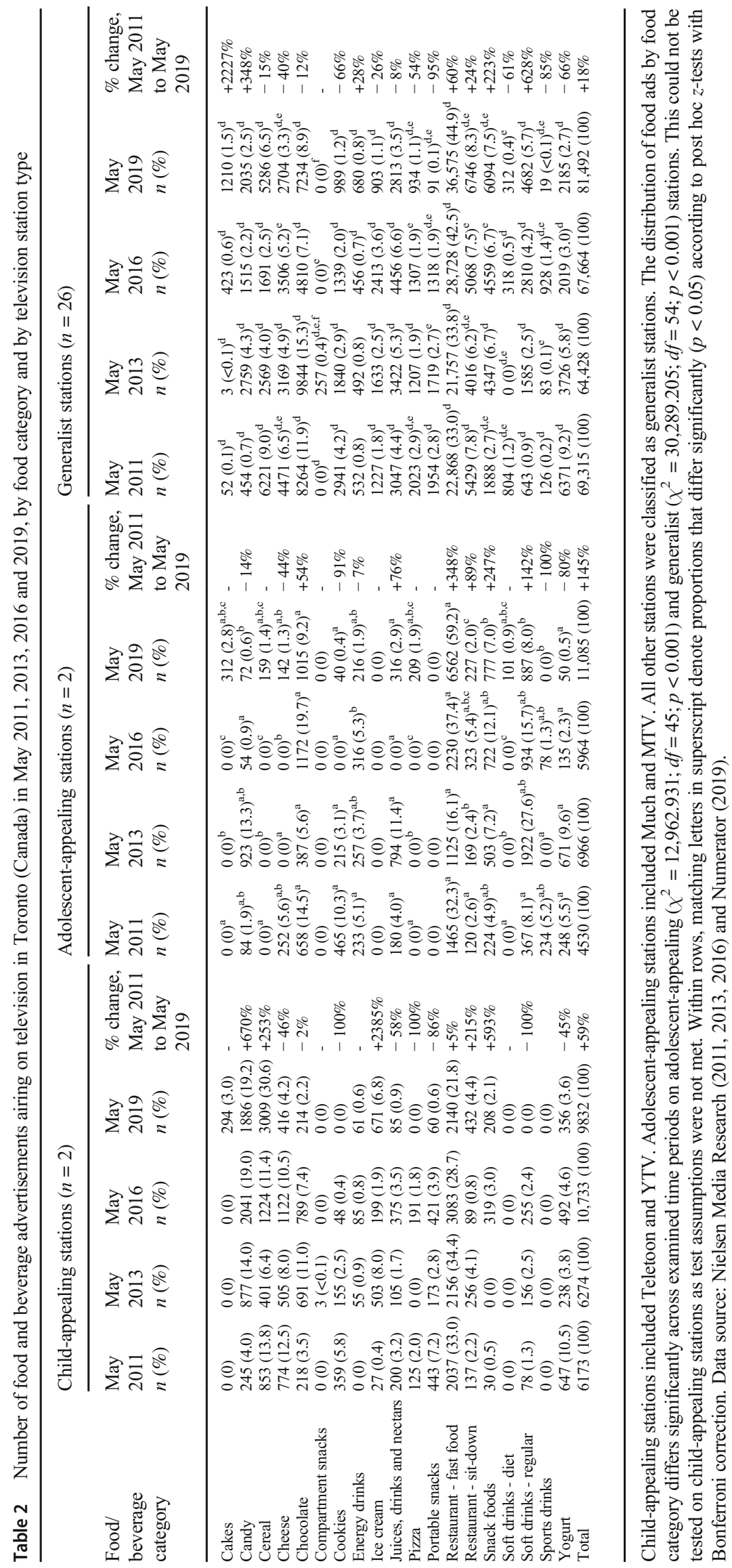


May of 2011, 2013, 2016 and 2019, respectively. On these stations, the distribution of ads by food category differed significantly across time $\left(\chi^{2}=12,962.931 ; d f=45 ; p<0.001\right)$. The most advertised food categories in May 2011 were fast food (32.3\% of total ads), chocolate (14.5\%) and cookies $(10.3 \%)$, while in May 2019, these were fast food (59.2\%), chocolate (9.2\%) and regular soft drinks (8.0\%). Between May 2011 and May 2019, the total number of food advertisements on adolescent-appealing stations increased by $145 \%$. The greatest relative increases between these two periods occurred for fast food $(+348 \%)$ and snack foods $(+247 \%)$, while the largest relative decreases were noted for sports drinks $(-100 \%)$ and cookies $(-91 \%)$. The largest absolute increases between these two periods were noted for fast food $(+5097$ ads), snack foods $(+553)$ and regular soft drinks $(+520)$, while the largest absolute decreases were noted for cookies $(-425)$ and sports drinks $(-234)$. For most food categories, there was no consistent temporal trend in advertising frequency across all examined periods. Only the number of snack food advertisements increased steadily over time. Ice cream and portable and compartment snacks were not at all advertised on adolescent-appealing stations across all examined periods.

On generalist stations, a total of 69,315, 64,428, 67,664 and 81,492 food advertisements aired in May of 2011, 2013, 2016 and 2019, respectively. On these stations, the distribution of ads by food category differed significantly across time $\left(\chi^{2}=\right.$ 30,289.205; $d f=54 ; p<0.001)$. The most advertised food categories in May 2011 were fast food (33.0\% of total ads), chocolate $(11.9 \%)$ and yogurt (9.2\%), while in May 2019, these were fast food $(44.9 \%)$, chocolate $(8.9 \%)$ and sit-down restaurants $(8.3 \%)$. Between May 2011 and May 2019, the number of food advertisements on generalist stations increased by $18 \%$. The greatest relative increases between these two periods occurred for cakes $(+2227 \%)$ and regular soft drinks $(+628 \%)$, while the largest relative decreases were noted for portable snacks $(-95 \%)$ and sports drinks (-85\%). The largest absolute increases between these two periods were noted for fast food (+13,707 ads), snack foods (+4206) and regular soft drinks (+4039), while the largest absolute decreases were noted for yogurt $(-4186)$, cookies $(-1952)$ and portable snacks $(-1863)$. The absolute and relative frequency of ads promoting snack foods and regular soft drinks increased steadily across all examined periods while decreasing steadily for cookies and portable snacks. No other consistent temporal trends among food categories were noted.

\section{Changes in children's food advertising exposure, overall and by station category}

On average, children were exposed to 170, 150, 162 and 136 food advertisements in May of 2011, 2013, 2016 and 2019, respectively (Table 3 ). The food categories to which children were the most exposed in May 2011 were fast food $31.3 \%$ of total exposure), cereal (13.6\%) and yogurt (9.4\%), while in
May 2019, these were fast food (43.0\%), cereal (10.9\%) and sit-down restaurants $(8.8 \%)$. Children's overall exposure to food advertising decreased by $20 \%$ or 33.8 ads per child between May 2011 and May 2019. While exposure decreased greatly in relative terms for some food categories, such as portable snacks $(-97 \%)$ and cookies $(-89 \%)$, others, such as regular soft drinks $(+495 \%)$, cakes $(+481 \%)$ and snack foods $(+279 \%)$, increased markedly. In absolute terms, children's exposure increased the most between May 2011 and May 2019 for snack foods (+7.2 ads/child), fast food (+5.4) and regular soft drinks (+5.3), while decreasing the most for yogurt $(-12.7$ ads/child), cheese $(-10.2)$ and portable snacks $(-10.2)$. Children's exposure in both relative and absolute terms decreased steadily across all examined periods for cookies, pizza and yogurt while increasing steadily for snack foods and regular soft drinks.

As shown in Table 4, changes in children's overall exposure to food advertising also differed by station category. Children's total exposure decreased between May 2011 and May 2019 by $59 \%$ ( -33.5 ads/child) and 3\% (-3.5 ads/child) on childappealing and generalist stations, respectively, while increasing by $237 \%(+3.1$ ads/child) on adolescent-appealing stations. Children's exposure to fast food and regular soft drink advertising decreased on child-appealing stations ( $-68 \%$ or -10.8 ads/ child and $-100 \%$ or -0.3 ads/child, respectively) but increased on adolescent-appealing ( $+600 \%$ or +2.2 ads/child and $+50 \%$ or $+0.1 \mathrm{ad} /$ child, respectively) and generalist stations $(+38 \%$ or +14.0 ads/child and $+884 \%$ or +5.5 ads/child, respectively). For other food categories such as snack foods and sit-down restaurants, greater absolute increases in children's exposure also occurred on generalist stations $(+7.0$ and +2.6 ads/child, respectively) compared with child-appealing stations (+0.02 and +0.2 ads/child, respectively).

In May 2019, 17.3\% of children's overall exposure to food advertising occurred while watching child-appealing stations (Table 5). The predominant source of exposure by station type varied among food categories. Most of children's exposure to candy (76\% of exposure), cereal $(55 \%)$ and portable snack (59\%) advertisements in May 2019 occurred on childappealing stations. Conversely, most of children's exposure to all other food categories, including regular soft drinks (100\% of exposure), snack foods $(97 \%)$, chocolate $(96 \%)$, sit-down restaurants $(93 \%)$ and fast food restaurants $(92 \%)$, occurred on adolescent-appealing or generalist stations.

\section{Discussion}

Our study found that children in Toronto viewed on average 136 food ads in May 2019, 34 fewer than in May 2011. Despite this decline, one could conservatively estimate that children viewed at least 1700 food advertisements in 2019 on television alone, adding to and likely heightening the effects of other sources of food advertising exposure (Luxton et al., 2015; Norman et al., 
Table 3 Children's exposure to food and beverage advertisements on 30 stations broadcast in Toronto (Canada) in May of 2011, 2013, 2016 and 2019, by food category

Food/beverage category Average number of advertisements viewed by children (aged 2-11 years)

\begin{tabular}{|c|c|c|c|c|c|}
\hline May 2011, $n(\%)$ & May $2013, n(\%)$ & May $2016, n(\%)$ & May $2019, n(\%)$ & $\begin{array}{l}\text { \% change, } \\
\text { May } 2011 \text { to } \\
\text { May } 2019\end{array}$ & $\begin{array}{l}\text { Absolute difference, } \\
\text { May } 2019 \text { vs } \\
\text { May } 2011\end{array}$ \\
\hline
\end{tabular}

\begin{tabular}{|c|c|c|c|c|c|c|}
\hline Cakes & $0.27(0.2)$ & $0(0)$ & $0.69(0.4)$ & $1.57(1.2)$ & $+481 \%$ & +1.3 \\
\hline Candy & $4.18(2.5)$ & $11(7.3)$ & $13.03(8.1)$ & $7.74(5.7)$ & $+85 \%$ & +3.6 \\
\hline Cereal & $23.23(13.6)$ & $9.11(6.1)$ & $12.59(7.8)$ & $14.81(10.9)$ & $-36 \%$ & -8.4 \\
\hline Cheese & $14.18(8.3)$ & $11.05(7.3)$ & $12.27(7.6)$ & $4.02(2.9)$ & $-72 \%$ & -10.2 \\
\hline Chocolate & $12.71(7.5)$ & $14.64(9.7)$ & $7.85(4.9)$ & $8.57(6.3)$ & $-33 \%$ & -4.1 \\
\hline Compartment snacks & $0(0)$ & $0.31(0.2)$ & $0(0)$ & $0(0)$ & - & 0.0 \\
\hline Cookies & $6.18(3.6)$ & $3.86(2.6)$ & $2.24(1.4)$ & $0.7(0.5)$ & $-89 \%$ & -5.5 \\
\hline Energy drinks & $0.96(0.6)$ & $0.88(0.6)$ & $1.24(0.8)$ & $1.35(1.0)$ & $+41 \%$ & +0.4 \\
\hline Ice cream & $2.31(1.4)$ & $3.5(2.3)$ & $4.42(2.7)$ & $1.09(0.8)$ & $-53 \%$ & -1.2 \\
\hline $\begin{array}{l}\text { Juices, drinks and } \\
\text { nectars }\end{array}$ & $7.32(4.3)$ & $8.03(5.3)$ & $7.93(4.9)$ & $3.68(2.7)$ & $-50 \%$ & -3.6 \\
\hline Pizza & $4.85(2.8)$ & $2.12(1.4)$ & $2.05(1.3)$ & $1.08(0.8)$ & $-78 \%$ & -3.8 \\
\hline Portable snacks & $10.48(6.2)$ & $4.53(3.0)$ & $5.05(3.1)$ & $0.27(0.2)$ & $-97 \%$ & -10.2 \\
\hline Restaurant - fast food & $53.29(31.3)$ & $52.99(35.2)$ & $64.45(39.9)$ & $58.68(43.0)$ & $+10 \%$ & +5.4 \\
\hline Restaurant - sit-down & $9.03(5.3)$ & $9.87(6.6)$ & $7.4(4.6)$ & $11.94(8.8)$ & $+32 \%$ & +2.9 \\
\hline Snack foods & $2.59(1.5)$ & $5.09(3.4)$ & $6.99(4.3)$ & $9.81(7.2)$ & $+279 \%$ & +7.2 \\
\hline Soft drinks - diet & $1.1(0.6)$ & - & $0.66(0.4)$ & $0.54(0.4)$ & $-51 \%$ & -0.6 \\
\hline Soft drinks - regular & $1.06(0.6)$ & $3.62(2.4)$ & $5.5(3.4)$ & $6.31(4.6)$ & $+495 \%$ & +5.3 \\
\hline Sports drinks & $0.55(0.3)$ & $0.31(0.2)$ & $1.57(1.0)$ & $1.04(0.8)$ & $+89 \%$ & +0.5 \\
\hline Yogurt & $15.93(9.4)$ & $9.57(6.4)$ & $5.65(3.5)$ & $3.19(2.3)$ & $-80 \%$ & -12.7 \\
\hline Total & $170.2(100)$ & $150.5(100)$ & $161.6(100)$ & $136.4(100)$ & $-20 \%$ & -33.8 \\
\hline
\end{tabular}

Data source: Nielsen Media Research (2011, 2013, 2016) and Numerator (2019).

2018). While we did not assess the healthfulness of promoted food products, clearly unhealthy food categories such as fast food, candy, chocolate, snack foods and regular soft drinks constituted more than half of children's overall exposure in May 2019. Consistent with previous research, these findings further emphasize the failure of industry self-regulation in protecting Canadian children from exposure to unhealthy food advertising on television (Potvin Kent et al., 2011a; Kelly et al., 2019; Potvin Kent \& Wanless, 2014; Potvin Kent et al., 2018).

Interestingly, children's $20 \%$ decline in food advertising exposure occurred despite 22,000 additional food ads airing in May 2019 compared with May 2011 across examined stations. Shifts in exposure however varied by station category. Children's exposure on child-appealing stations decreased by $59 \%$ even though ad frequency increased in equal measure $(+59 \%)$. In contrast, children's exposure on adolescent-appealing stations increased $237 \%$, in tandem with a $145 \%$ increase in ad frequency, while remaining relatively constant on generalist stations, decreasing by only $3 \%$ despite an $18 \%$ increase in ads. As advertising exposure is dependent on both the volume and placement of advertisements as well as media consumption, children's changing viewership behaviours are likely responsible for this decline. Children's viewership of broadcast television did in fact decrease in recent years, going from an average of $22.2 \mathrm{~h}$ per week to $17.3 \mathrm{~h}$ per week between 2011-2012 and 2017-2018 (CRTC, 2020; CRTC, 2017). Children are likely consuming more television content, particularly children's programming, via streaming platforms such as YouTube, Netflix and Disney+ . As a result, one could expect their food advertising exposure from broadcast television to continue to decline over time. Although Netflix and Disney+ are free of traditional advertising, the fragmentation of television content across these multiplying platforms and the cost tied to their access may contribute to disparities in exposure between children of lower and higher income households. At the same time, children watching content on streaming platforms with advertising may be viewing more persuasive food promotions as metadata and behavioural targeting are being used to deliver highly personalized advertisements (World Health Organization, 2016). Despite the emergence of these newer platforms, broadcast television remains a significant source of advertising exposure that merits continued monitoring. Additional research is also needed to monitor advertising practices and exposure on streaming television. 


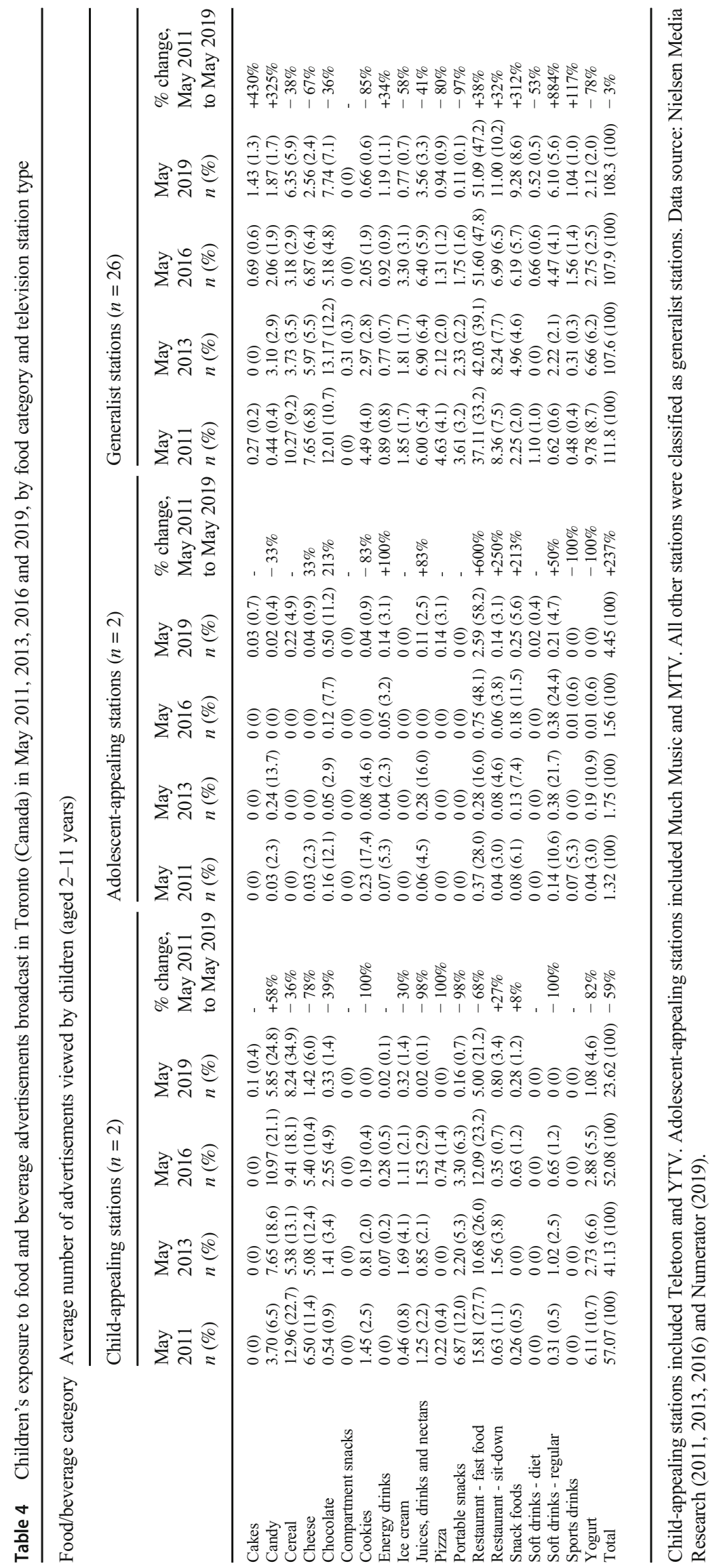


Table 5 Share of children's exposure to food and beverage advertising viewed on child-appealing stations versus other stations in Toronto (Canada) in May 2019, overall and within food categories

\begin{tabular}{|c|c|c|c|c|c|}
\hline \multirow[t]{2}{*}{ Food/beverage category } & \multicolumn{2}{|c|}{ Child-appealing stations $(n=2)$} & \multicolumn{2}{|l|}{ Other stations $(n=28)$} & \multirow[t]{2}{*}{ Total exposur } \\
\hline & $\begin{array}{l}\text { Avg number of ads } \\
\text { viewed/child aged 2-11 }\end{array}$ & $\begin{array}{l}\% \text { of total exposure } \\
\text { within the food category }\end{array}$ & $\begin{array}{l}\text { Avg number of ads } \\
\text { viewed/child aged 2-11 }\end{array}$ & $\begin{array}{l}\% \text { of total exposure } \\
\text { within the food category }\end{array}$ & \\
\hline Cakes & 0.1 & 6.4 & 1.47 & 93.6 & 1.57 \\
\hline Candy & 5.85 & 75.6 & 1.89 & 24.4 & 7.74 \\
\hline Cereal & 8.24 & 55.6 & 6.57 & 44.4 & 14.81 \\
\hline Cheese & 1.42 & 35.3 & 2.6 & 64.7 & 4.02 \\
\hline Chocolate & 0.33 & 3.9 & 8.24 & 96.1 & 8.57 \\
\hline Compartment snacks & 0 & - & 0 & - & 0.0 \\
\hline Cookies & 0 & 0.0 & 0.7 & 100 & 0.7 \\
\hline Energy drinks & 0.02 & 1.5 & 1.33 & 98.5 & 1.35 \\
\hline Ice cream & 0.32 & 29.4 & 0.77 & 70.6 & 1.09 \\
\hline Juices,drinks and nectars & 0.02 & 0.5 & 3.66 & 99.5 & 3.68 \\
\hline Pizza & 0 & 0.0 & 1.08 & 100.0 & 1.08 \\
\hline Portable snacks & 0.16 & 59.3 & 0.11 & 40.7 & 0.27 \\
\hline Restaurant - fast food & 5.00 & 8.5 & 53.68 & 91.5 & 58.68 \\
\hline Restaurant - sit-down & 0.80 & 6.7 & 11.14 & 93.3 & 11.94 \\
\hline Snack foods & 0.28 & 2.9 & 9.53 & 97.1 & 9.81 \\
\hline Soft drinks - diet & 0 & 0.0 & 0.54 & 100 & 0.54 \\
\hline Soft drinks - regular & 0 & 0.0 & 6.31 & 100 & 6.31 \\
\hline Sports drinks & 0 & 0.0 & 1.04 & 100 & 1.04 \\
\hline Yogurt & 1.08 & 33.9 & 2.11 & 66.1 & 3.19 \\
\hline Total & 23.6 & 17.3 & 112.8 & 82.7 & 136.4 \\
\hline
\end{tabular}

Child-appealing stations included Teletoon and YTV. Data source: Nielsen Media Research (2011, 2013, 2016) and Numerator (2019).

Notably, our study found that $83 \%$ of advertisements viewed by children occurred on stations that appeal to older youth or are intended for general audiences, with the greatest absolute increases in exposure for some unhealthy food categories (e.g., snack foods) occurring on generalist stations. In some instances, decreases in advertisement frequency or exposure that occurred on child-appealing stations were offset by increases in advertising and exposure on generalist stations. Such was the case for fast food. Between May 2011 and May 2019, children's exposure to fast food advertising decreased on average by 11 ads per child on child-appealing stations, where ad frequency remained fairly stable, while increasing on average by 14 ads per child on generalist stations, where the number of fast food advertisements increased by $60 \%$. Similarly, even though regular soft drinks were not at all advertised on child-appealing stations in May 2019, ad exposure for these beverages reached its highest during the same period, with the near totality of this increase occurring on generalist stations where the number of soft drink ads was also at its highest. These findings illustrate that children's exposure to unhealthy food advertising can increase even when such advertising remains stable or is absent from stations intended for young audiences.

Given that generalist stations accounted for a large share of children's exposure, food advertising restrictions currently being considered by the federal government need to be designed such that children are adequately protected from unhealthy food advertising on programming that appeal to broad audiences. Based on policy evaluations from the United Kingdom, where unhealthy food advertising to children under 16 has been restricted on broadcast television since 2007, a recent World Health Organization report concluded that food advertising restrictions need to apply during programs that reach large absolute numbers of children, regardless of their intended audience, to be effective (Boyland et al., 2018). To increase the effectiveness of their restrictions, the UK is in fact expected to prohibit unhealthy food advertising airing before $9 \mathrm{pm}$ on all broadcast television stations (Sweney, 2020). Canadian policymakers should consider heeding the lessons learned from abroad when crafting food advertising restrictions and ensure that Canadian children are also protected on television stations that appeal to broad audiences and not simply on child-appealing stations.

\section{Strengths and limitations}

The limitations of our study are important to underscore. To start, our estimate of children's exposure to food advertising is likely underestimated and may not be representative of children's overall exposure on broadcast television. Our study only included advertisements for 19 food categories broadcast in Toronto on the 30 stations that were consistently recorded and monitored by Nielsen or Numerator across time. This led to the exclusion of the Disney Channel, a popular child-appealing station, for which data were only available for May 2019. As we only examined 4 weeks of advertising per year in one Canadian city, our 
estimate of exposure is likely not representative of all Canadian children and does not account for seasonal variations in advertising frequency and content (Pinto et al., 2020). Our study also excludes exposure to food product or brand appearances that can be seen during sponsored sporting events and other television programming (Elsey \& Harris, 2016; Sherriff et al., 2010). While classifying advertisements into mutually exclusive food categories allowed us to test differences in the distribution of food ads across time, it did result in the underestimation of ad frequency and exposure of two food categories, namely portable snacks and diet soft drinks. Finally, given that advertising exposure data are only available in aggregate, statistical testing of differences across time and between station categories could not be performed. Future studies that measure children's exposure objectively or through self-reporting should conduct multivariable analyses to investigate disparities in exposure among subgroups of interest (e.g., children from lower vs higher income households). Notwithstanding these limitations, our study provided recent estimates of food advertising exposure among Canadian children using measured media data and examined trends over time.

\section{Conclusion}

Canadian children under 12 years of age are exposed to many food advertisements promoting unhealthy food categories on television and most of this exposure is occurring on generalist stations. Statutory restrictions currently being considered by Canadian policymakers should be designed such that children are adequately protected from unhealthy food advertising on both stations intended for general audiences and those targeting younger audiences.

\section{Contributions to knowledge}

What does this study add to existing knowledge?

- This study provides recent estimates of children's exposure to food advertising on broadcast television in a Canadian context and describes changes in exposure over time.

- Although children's overall exposure to food advertising decreased between May 2011 and May 2019, their exposure remained high in 2019 and unhealthy food categories still accounted for most of this exposure.

- Most of children's exposure to food advertising also stemmed from stations intended for general audiences, and their exposure to some unhealthy food categories (e.g., fast food and soft drinks) increased even when such advertising remained relatively stable or was absent from stations intended for young audiences.
What are the key implications for public health interventions, practice or policy?

- Industry self-regulation is not protecting Canadian children from exposure to unhealthy food advertising on broadcast television.

- Restricting the advertising of unhealthy food and beverages on child-appealing stations alone will not adequately protect them from such advertising.

- Statutory restrictions should be adopted and designed such that children are effectively protected from unhealthy food advertising on both stations intended for general audiences and those that appeal to younger audiences.

Supplementary Information The online version contains supplementary material available at https://doi.org/10.17269/s41997-021-00528-1.

Availability of data and material The data analyzed in this study were obtained under licence and cannot be shared.

Author contributions EP and MPK designed the study. EP conducted the analyses and drafted the manuscript. MPK reviewed the manuscript.

Funding Elise Pauzé is supported by the Canada Graduate Scholarship to Honour Nelson Mandela awarded by the Canadian Institutes of Health Research. Funding was provided for data licencing by the Public Health Agency of Canada, the Faculty of Medicine of the University of Ottawa, and Health Canada.

\section{Declarations}

Ethics approval Non-applicable. This paper analyzed licenced advertisement viewership data which are only available in aggregate.

Consent to participate N/A.

Consent for publication N/A.

Conflict of interest In 2018, Elise Pauzé received a small honorarium from the Stop Marketing to Kids Coalition, a coalition of leading health organizations, for reviewing policy recommendations and supporting evidence. In 2020, she was also employed by Health Canada, on a casual basis, to conduct research on food marketing in Canada.

Disclaimer Funders had no role in designing the study, conducting the analyses, interpreting the findings and drafting the article nor the decision to publish.

Open Access This article is licensed under a Creative Commons Attribution 4.0 International License, which permits use, sharing, adaptation, distribution and reproduction in any medium or format, as long as you give appropriate credit to the original author(s) and the source, provide a link to the Creative Commons licence, and indicate if changes were made. The images or other third party material in this article are included in the article's Creative Commons licence, unless indicated otherwise in a credit line to the material. If material is not included in the article's Creative Commons licence and your intended use is not permitted by statutory regulation or exceeds the permitted use, you will need to obtain permission directly from the copyright holder. To view a copy of this licence, visit http://creativecommons.org/licenses/by/4.0/. 


\section{References}

Ad Standards. (2019). The Canadian Children's Food and Beverage Advertising Initiative. 2018 Compliance report. Available from: https://adstandards.ca/wp-content/uploads/2020/01/AdStandardsCAI-Compliance-Report-18-EN.pdf. Accessed August 2020.

Birch, L., Savage, J. S., \& Ventura, A. (2007). Influences on the development of children's eating behaviours: From infancy to adolescence. Canadian Journal of Dietetic Practice and Research, 68(1), s1-s56.

Boyland, E., Garde, A., Jewell, J., \& Tatlow-Golden, M. (2018). Evaluating implementation of the WHO set of recommendations on the marketing of foods and non-alcoholic beverages to children. Geneva: WHO. http://www.euro.who.int/_data/assets/pdf file/ 0003/384015/food-marketing-kids-eng.pdf. Accessed August 2020.

Canadian Radio-Television and Telecommunications Commission (CRTC). (2017). Communications Monitoring Report 2017. Ottawa: CRTC. https://crtc.gc.ca/eng/publications/reports/ PolicyMonitoring/2017/cmr2017.pdf. Accessed August 2020.

Canadian Radio-Television and Telecommunications Commission (CRTC). (2020). Communications Monitoring Report 2019. Ottawa: CRTC. https://crtc.gc.ca/pubs/cmr2019-en.pdf. Accessed April 2021.

Canadian Society for Exercise Physiology. (2016). Canadian 24-hour movement guidelines for children and youth: An integration of physical activity, sedentary behaviour and sleep. https:// csepguidelines.ca/wp-content/themes/csep2017/pdf/ Canadian24HourMovementGuidelines2016 2.pdf. Accessed 16 March 2021.

Carter, O. B., Patterson, L. J., Donovan, R. J., Ewing, M. T., \& Roberts, C. M. (2011). Children's understanding of the selling versus persuasive intent of the selling persuasive intent of junk food advertising: Implications for regulation. Social Science and Medicine, 72(6), 962-968.

Elsey, J. W. B., \& Harris, J. L. (2016). Trends in food and beverage television brand appearances viewed by children and adolescents from 2009 to 2014 in the USA. Public Health Nutrition, 19(11), $1928-1933$.

Garde, A., Byrne, S., Gokani, N. \& Murphy, B. (2018). A child rightsbased approach to food marketing: A guide for policy maker. United Nations Children's Fund (UNICEF). https://www.unicef.org/csr/ files/A_Child_Rights-Based_Approach_to_Food_Marketing Report.pdf. Accessed November 2020.

Health Canada. (2018). Application of the Child Health Protection Act (Bill S-228). Engagement session. December 14, 2018. https:// www.canada.ca/en/services/health/campaigns/vision-healthycanada/healthy-eating/meetings-correspondence.html. Accessed April 2021

Institute for Health Metrics and Evaluation. (2019). Canada. http://www. healthdata.org/canada. Accessed November 2020.

Jessri, M., Nishi, S. K., \& L'Abbé, M. R. (2016). Assessing the nutritional quality of diets of Canadian children and adolescents using the 2014 Health Canada Surveillance Tool Tier System. BMC Public Health, 16, 381.

Kelly, B., Vandevijvere, S., Ng, S. H., Adams, J., Allemandi, L., BahenaEspina, L., Barquera, S., et al. (2019). Global benchmarking of children's exposure to television advertising of unhealthy foods and beverages across 22 countries. Obesity Reviews 20(Suppl 2), $116-128$.
Luxton, S., Reid, M., \& Mavondo, F. (2015). Integrated marketing communication capability and brand performance. Journal of Advertising, 44(1), 37-46.

McGinnis, J. M., Gootman, J., \& Kraak, V. I. (Eds.). (2006). Food marketing to children and youth: Threat or opportunity. Washington, DC: The National Academies Press.

Moubarac, J. C. (2017). Ultra-processed foods in Canada: consumption, impact on diet quality and policy implications. Montréal: Transnut, Université de Montréal. https://www.heartandstroke.ca/-/media/pdffiles/canada/media-centre/hs-report-upp-moubarac-dec-5-2017. ashx. Accessed August 2020.

Norman, J., Kelly, B., Boyland, E., \& McMahon, A.-T. (2016). The impact of marketing and advertising on food behaviours: Evaluating the evidence for a causal relationship. Current Nutrition Report, 5, 139-149.

Norman, J., Kelly, B., McMahon, A.-T., \& Boyland, E. J. (2018). Sustained impact of energy-dense TV and online food advertising on children's dietary intake: A within-subject, randomised, crossover, counter-balanced trial. International Journal of Behavioral Nutrition and Physical Activity, 15(1), 37.

Office of the Prime Minister. (2019). Minister of Health Mandate Letter. https://pm.gc.ca/en/mandate-letters/2019/12/13/minister-healthmandate-letter. Accessed August 2020.

Pinto, A., Pauzé, E., Mutata, R., Roy-Gagnon, M.-H., \& Potvin Kent, M. (2020). Food and beverage advertising to children and adolescents on television: A baseline study. International Journal of Environmental Research and Public Health, 17(6), 1999.

Potvin Kent, M., Dubois, L., \& Wanless, A. (2011a). Self-regulation by industry of food marketing is having little impact during children's preferred television. International Journal of Pediatric Obesity, 6(5-6), 401-408.

Potvin Kent, M., Dubois, L., \& Wanless, A. (2011b). Food marketing on children's television in two different policy environments. International Journal of Pediatric Obesity, 6(2), 433-441.

Potvin Kent, M., \& Wanless, A. (2014). The influence of the Children's Food and Beverage Advertising Initiative: Change in children's exposure to food advertising on television in Canada between 20062009. International Journal of Obesity, 38(4), 558-562.

Potvin Kent, M., Smith, J. R., Pauzé, E., \& L’Abbé, M. (2018). The effectiveness of the food and beverage industry's self-established Uniform Nutrition criteria at improving the healthfulness of food advertising viewed by Canadian children on television. International Journal of Behavioral Nutrition and Physical Activity, 15(1).

Rao, D. P., Kropac, E., Do, M. T., Roberts, K. C., \& Jayaraman, G. C. (2016). Childhood overweight and obesity trends in Canada. Health Promotion and Chronic Disease Prevention in Canada, 36(9), 194 198.

Sadeghirad, B., Duhaney, T., Motaghipisheh, S., Campbell, N. R. C., \& Johnson, B. C. (2016). Influence of unhealthy food and beverage marketing on children's dietary intake and preference: A systematic review and meta-analysis of randomized trials. Obesity Reviews, $17(10), 945-959$.

Senate of Canada. (2017). BILL S-228 (Third Reading). https://www.parl. $\mathrm{ca} /$ DocumentViewer/en/42-1/bill/S-228/third-reading. Accessed November 2020.

Sherriff, J., Griffiths, D., \& Daube, M. (2010). Cricket: Notching up runs for food and alcohol companies? Australian and New Zealand Journal of Public Health, 34(1), 19-23.

Sweney, M. (2020). UK set to bring in strict new junk food rules including pre-9pm ad ban. The Guardian. https://www.theguardian.com/ 
society/2020/jul/23/new-rules-on-junk-food-ads-could-threaten-ukeconomic-recovery. Accessed October 2020.

Wilcox, B. L., Kunkel, D., Cantor, J., Dowrick, P., Linn, S., Palmer, E. Report of the APA Task Force on advertising and children. pp. 64, 2004. http://www.apa.org/pi/families/resources/advertisingchildren.pdf. Accessed August 2017.

World Health Organization. (2010). Set of recommendations on the marketing of foods and non-alcoholic beverages to children. Resolution of the Sixty-third World Health Assembly WHA63.14 Marketing of food and non-alcoholic beverages to children. Geneva: WHO.
World Health Organization's Regional Office for Europe. (2016). Tackling food marketing to children: trans-disciplinary perspectives. https://www.euro.who.int/_data/assets/pdf_file/ 0017/322226/Tackling-food-marketing-children-digital-worldtrans-disciplinary-perspectives-en.pdf. Accessed March 2021.

Publisher's note Springer Nature remains neutral with regard to jurisdictional claims in published maps and institutional affiliations. 